\title{
Geleneğin Sürekliliği ve Kültürel Mirasın Aktarımında Niğde Düğünleri ve Müzisyenler
}

\author{
DOI: 10.26466/opus.593570
}

\begin{abstract}
$*$
$\underline{\text { Resul Bağ } 1^{*}}$

*Dr. Öğr. Üyesi Niğde Ömer Halisdemir Üniversitesi, Türk musikisi Devlet konservatuarı, Niğde/ Türkiye E-Posta: resulbagi@gmail.com

ORCID: 0000-0002-9325-2455
\end{abstract}

\section{Öz}

Niğde dü̆̆̈̈n törenleri müzisyenlerin çaldıkları enstrümanlar ve söyledikleri türküler açısından geleneğin korunması ve aktarlmasında önemli bir yere sahiptir. Niğde ilinin güçlü bir müzisyenlik geleneğine ev sahipliği yapması ve birçok müzisyenin bu çevrede yetişmiş olması çalışmanın odak noktasını teşkil etmektedir. Niğgde ilinde yapılan düğ̈̈̈n ritüelleri günümüzde halen devam eden sokak dü̆̆̈̈̈nlerinde gerek gün içerisindeki süre uzunluğu ile gerekse düğünlerde halen devam eden Türk halk müziği repertuvarmdaki geleneksel anonim türkülerin-uzun hava ve kırık havalar- okunuyor olması açısından ülkemizdeki pek çok düğ̈̈n ritüelinden

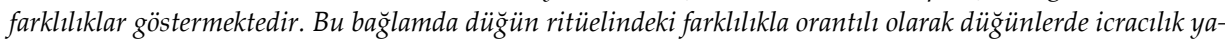
pan müzisyenlerin uygulamalarn da bu oranda farklllklara gebedir. Bu farklllkklarm neticesi olarak Niğde dü̈̆̈̈nleri geleneğin sürekliliği açısından büyük önem arz etmekte ve bu dü̆̈̈ülerde müzisyenlik yapanlarda kültürrel aktarıcl görevi görmektedir. Ayrıca coğrafi olarak küçük bir alana sahip olan Niğde'de 3 farklı düğ̈̈n kültürünün bulunması da çalışmayı önemli kılmaktadır. Çalışmanın amacı, düğün müzisyenliğinin genel tanımından hareketle, yöre müzisyenlerinin düğün içerisindeki konumlarımı, müziksel pratiklerini, belleklerinde saklı kalmış edebi metinleri ve bu metinlerden kopan türküleri tespit etmek ve Niğde düğün tipleri üzerinden günümüzdeki düğ̈̈nlerin genel durumunu gözler önüne sermektir.

Anahtar Kelimeler: Niğde Düğ̈̈n Geleneği, Geleneğgin Sürekliliği, Kültürel Mirasın Aktarımı, Düğün Müzisyenleri. 


\title{
Sustainability of Tradition and Nigde Weddings and Musicians in Transfer of Cultural Heritage
}

\begin{abstract}
In Nigde, wedding ceremonies, instruments played by musicians and the songs they sing have an important place in preserving and transmitting the tradition. Niğde is the focal point of the study as it hosts a strong tradition of musicianship and many musicians have grown up in this environment. Wedding rituals performed in Niğde vary according to many wedding rituals in our country in terms of both the length of the day during the day and the traditional anonymous folk songs of the Turkish Folk Music repertoire, long and broken melody, which continue at the weddings. In this context, the practices of musicians performing at weddings in proportion to the difference in wedding ritual are also suitable for these differences. As a result of these differences, Niğde weddings are of great importance for the sustainability of tradition and act as cultural transmitters for musicians in these weddings. In addition, the fact that there are 3 different wedding cultures in Niğde, which has a small geographic area, gives a special importance to the study. The aim of this study is to determine the position of the musicians in the wedding, their musical practices, the literary texts that are hidden in their memories and the songs that are lost from these texts and to evaluate the general situation of the present day weddings through the types of weddings.
\end{abstract}

Keywords: Niğde Wedding Tradition, Sustainability of Tradition, Transfer of Cultural Heritage, Wedding Musicians. 


\section{Giriş}

İbrahim Tatllses 2 saat sahnede kalsa rekor sayılır oysaki Niğde müzisyenleri 3 gün durmaksızın düğ̈̈n yaparak asıl rekoru kırmaktadır.

Eğer kültür bir sosyal grubun üyelerinin birbirinden öğrendiği veya birbiriyle paylaştığı, çevreye uyarlanmada arabulucu işlevi gördüğü ve bir nesilden diğerine sosyal öğrenme yoluyla aktarıldığı uygulamalar olarak tanımlanırsa (Lavenda ve Schultz, 2017, s.49) gelenek sürekliliğinde müzikal dinamikliğin önemli görevleri vardır. Etnomüzikologlar müziklerin sadece arşivlenmesi ve korunması odaklı değil bu verilerin dinamikliği konusunda da teşvik edici çalışmalar içerisindedir. Giderek artan şekilde dinamik bir yaklaşımı teşvik eden bu çalışmalarda düğünler başat görevi görmektedirler. Geleneğin sürekliliği, iyi bir mirası geçmişten korumak değil mevcut koşullara göre zenginleştirerek sonucun gelecek nesillere aktarılmasıdır. Ezgilerin otantikliği kalıtımsal bir performans ve yaratma geleneğiyle ilişkilidir. Bu da eserlerin koruma ve tanıtımını teşvik eder. Belirli zamanlarda dügün repertuvarlarında eski türkülerin bazı değişiklikler ile yeniden düzenlenmesi sanatsal üretim ve katılım uygulaması kadar önemlidir. Müzik, kabul edilebilir olmak için belirli özelliklere sahip olmalıdır, fakat bazılarının yalnızca bir repertuarın ana akımında bulunması gerekir (Nettl, 1983, s.18). Müzik pek çok ritüelde olduğu gibi düğünlerin vazgeçilmez unsurlarından birisidir. Dügüunler, yürek bütünlüğü ve yardımlaşma duygusu ile birbirine bağlı, Ata yadigarı gelenek ve görenekleri yaşatmak demektir (Ataman, 1992, s.IX). Dügüun ritüelleri genellikle, meslekleri çalgıcılık olan profesyonel müzisyenler tarafından gerçekleştirilmektedir. Geçimlerini düğünlerde düğün müzisyenliği yaparak temin eden, yaşadıkları toplumsal çevrece "çalgıcı" olarak adlandırılan bu profesyonel müzisyenler (Berrakçay ve Yükselsin, 2015, s.1428), düğün ritüelleri bağlaminda "ritüel odaklı olan" ve "ritüel odaklı olmayan" birkaç müziksel rol üstlenir. Ritüel odaklı olan müziksel etkinlikler; dügünün başlangıç saati olan sabah saat 08.00 civarında başlayıp gece saat 24.00 'e -daha geç saatlerde olabilmektedir- kadar olan sürede dügüne gelen izler kitleyi dügüune motive eder. Ritüel odaklı olmayan müziksel etkinlikler ise, düğünü izlemeye gelen katılımclların 
müziksel beklentilerini karşılamaya yöneliktir. Dügün, ülkemizdeki geleneksel geçiş ritüellerinden (rites of passage) bir tanesidir ve günümüzde pek çok yörede ortalama iki gün sürmektedir. Çalışma konumuz olan Niğde ve çevresinde ise bu ritüel farklı gün sayıları ve farklı uygulamalar ile karşımıza çıkmaktadır. Bu ritüeller Niğdeli profesyonel müzisyenlerin katkılarıyla anlam kazanır. Niğde özelinde bu müzisyenler, büyük çoğunluğu bölgede yaşayan yine Niğdeli olan kişilerdir. Genellikle usta/çırak ilişkisi içerisinde mesleğe başlayan Niğdeli gençler ilerleyen yaşlarında bu işi profesyonel olarak sürdürmeye devam ederler. Hatta pek çoğunun tek geçim kaynağıdır. Niğdeli müzisyenler ritüel kapsamında temelde 3 farklı mekanda müzik hizmeti sunarlar: birincisi oda yada ev olarak tanımlanabilecek olan kapalı mekanda sabahın erken saatlerinden başlayıp ertesi gün ezan saati hatta gün doğumuna kadar süren yaklaşık 20 saatlik bir süreçte ritüel akışını belirli aşamalarda belirli havalarla kodlamak ve geçişe rehberlik etmek. İkincisi mahalle dügünü olarak da nitelendirilen gerek şehir merkezinde gerek köylerde dışarıda ve yine sabahın erken saatlerinde başlayıp gece yarısında biten ve yaklaşık 3 gün süren bir süreç. Üçüncüsü; gelişen teknolojik yaşam ve güncel ritüellere ayak uydurma amaçlı yapılan 2 gün süren salon dügünleridir.

Mahalle düğünleri, dügün salonlarının yaygınlaştığı dönemlere kadar yerel müziklerin yaygınlaşmasında, yerel geleneklerin canlı kalmasında ve maddi olmayan kültürel mirasın aktarımında önemli bir yere sahipti. Geleneğin sürekliliğinde geçmiş geleneğin hatırlatılması, yeniden yapılandırılışı ve yeni düzenin eskiyi hatırlatması önemlidir. Geleneklerde sönmüş kültürü anımsatmaktan ziyade var olanı canlandırmak daha büyük önem taşır. Dügünler, ülkemizde pek çok ilde, bir zamanlar aktif olarak kültürel geleneklerin sergilendiği ortamlar olan sokak

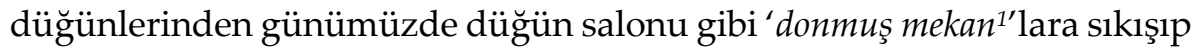
kalmıştır. Niğde de sokak dügünlerinin geleneksel usullerle halen sürüyor olması ve düğünlerde geleneksel THM örneklerinin sergilenmesi

\footnotetext{
${ }^{1}$ Mimari yapılardaki görüntü sadeliği aslında aldatıcıdır. Düğün salonunda dinler kitlenin müziğe bakış açııı ve kendisine sunulan müzikler morfogenetik alan içerisine sıkıştırılmışıı. Bu alanlarda morfik rezonansın oluşturduğu doğal bir hafıza oluşur ve dinleyici kitlesi gittiği her düğün salonunda karşılaşacağı müzik türünün bir önceki ile aynı yapıda olduğunu düşünmeye başlar. Örneğin düğün salonunda gördüğü klavye ve elektro bağlama hafızasına kazınır ve gideceği diğer düğün salonlarında da bu enstrümanlar ve dinlediği aynı müzik türü ile karşılaşacağını düşünür. Sonuç olarak müzik ve mekân dinler kitlenin psikolojik durumlarında eşdeğer bir rol oynar.
} 
kolektif hafıza egzersizleri ve hafızayı canlı tutma çabasıdır diyebiliriz. Bu nedenle bölgedeki düğünler kültürel çeşitliliği nedeniyle yöresel olarak kabul edilebilir ve teşvik edici yerlerdir. Dügünnler geleneğin sürekliliğinde kayıp ya da kaybolmakta olan ezgilerin yeniden yaşatılması ya da korumacı müdahalelerde akılcı bir tercih olacaktır. Bu tercih yalnızca yerel ve küresel kültürel manzaraların tamamlayıcı bir unsurudur. Düğünlerin değişen kimliği anonim ezgilerin süreğenliği, kullanımının yaygınlaşması açısından önemlidir. Bu bağlamda Niğde düğünlerinin önemi, anonim türkülerin -her ne kadar bazı değişikliklere uğramış olsa da- gelecek kuşaklara aktarılması ve korunmasında büyük önem taşımaktadır. Sokak dügünnlerinin giderek azalması yerel bir toplumda zarar verme, bir grubun bütünlüğü ve kimliği üzerinde olumsuz etkilere yol açma potansiyeline sahiptir.

Geleneğin sürekliliği açısından kültürel korumanın dinamik olması, buna bağlı olarak müzik icracıları ve düğünlere odaklanılması gerekmektedir. "Gelişimsel" veya 'yaşam döngüsü teorisi'nden doğan süreklilik teorisi, yaşlanan kişilerin, yaşamları boyunca geliştirdikleri aynı kişilikleri, alışkanlıkları ve bakış açılarını sürdürme ihtiyacı ve eğilimine sahip olduğunu iddia eder (Turner, 2006, s.13). Geleneklerin sürekliliği toplumların kendi kültür, örf ve adetlerine bağlı kalmalarıyla mümkündür. Niğgde il sınırları içerisinde devam eden mahalle dügünleri bu sürekliliğin devamlılığında önemli bir yer teşkil etmektedir. Dügünlerde yapılan eğlencelerde $\mathrm{THM}^{2}$ ezgilerinin ağırlıklı olarak çalınıp söyleniyor olması, THM geleneğinin devamlılığı açısından da büyük önem taşımaktadır. Günümüzde giderek yaygınlaşmaya başlayan düğün salonlarında popüler kültür ürünü ezgilerin ağırlıklı olarak çalınıp söyleniyor olması kültürün sürekliliğine büyük darbe vurmaktadır.

Niğde ve çevresini temelde üç bölüme ayırabiliriz. Bu ayrım temelde müzikal uygulamalar içeriklidir ve bu ayrım da kendi içerisinde farklılıklar içermektedir. Bu gruplandırmalar kesin sınırlar içermemekle birlikte müzikal etkinlikte kendine münhasır özellikler sergilemektedir. Örneğin davul zurna odaklı düğün kültürünün olduğu bölgede aynı zamanda elektro bağlama ve klavye eşlikli düğünde yapılmaktadır. Hepsinin neredeyse tek ortak noktası düğün sürelerinin Türkiye'nin diğer

2 Türk Halk Müziği 
bölgelerine oranla daha uzun olması olmasıdır. Gün boyunca THM eserleri -uzun hava ve kırık hava türküler- seslendirilerek dinler kitlenin türkü hafızası tazelenmektedir. Niğde ili dügün müzik kültürünü net çerçevelere oturtamamakla birlikte uygulama farklılıkları açısından şu şekilde siralayabiliriz.

Çamardı, Ulukışla, Melendiz ve Çiftlik; Davul-zurna odaklı halayın yaygın olduğu düğ̈ünler.

Bor ve çevresi; Elektro bağlama ve klavye eşliğinde yapılan düğünler.

Fertek ve Koyunlu; Renk saz diye tabir edilen Cümbüş, Keman, Klarnet ve darbuka enstrümanlarından oluşan düğün ekibi.

$\mathrm{Bu}$ çalışmada nitel araştırmaya dayalı ampirik bir çalışma biçimi ve etnografi temelli kültür analizi yöntemi benimsenmiştir. Çalışmada her bölgede en az bir müzisyen ile görüşme yapılmıştır. Yarı yapılandırılmış görüşme ve katılımcı gözlem teknikleriyle elde edilen tüm veriler edebiyatı, müziği ve retoriğiyle Niğde ve çevresindeki düğün geleneğinin günümüzdeki temsili varlığını teyit ederken, temelde paragmatik bir anlam taşıyan dügünncülügüun, modern yaşam koşulları altında simgesel bir anlam kazanmaya başladığını göstermektedir.

\section{Geleneğin Sürekliliği ve Kültürel Aracılık}

Müzikolojide teorik yaklaşımlar, toplumların doğasının yorumlanmasında önemli etkiye sahip olduğu için müzikolojik çalışmanın bilimsel meşruiyetini oluşturur. Bu nedenle çalışma konumuzu en uygun teori ya da teorilerle soyutlayarak açılamaya çalıştık. Çalışma konumuzda birden fazla teorik yaklaşımla Niğde dügün kültürü, düğün müzisyenleri ve bunlara bağlı olarak gelişen pratikler tartışmaya açılmıştır. Buna göre teorik yaklaşımlarımız Niğde müziğinin ontolojik yapısına katkı sağlayan geleneğin sürekliliği ve kültürel aracılık olgusu olmuştur. Geleneklerin sürekliliği toplumların kendi kültür örf ve adetlerine bağlı kalmalarıyla mümkündür. Niğde ve çevresinde halen devam eden mahalle dügünleri bu sürekliliğin devamlılığında önemli bir yer teşkil etmektedirler.

"Bir kültürün devamlılığı ve dayanıklılığı elindeki "kültürel sermayenin gücüne bağlıdır. Bu sermayenin arttırılması, yani güçlendirilmesi ise 
kültürel arac1lıkla mümkündür (Yükselsin, 2014, s.716)”. Geleneğin sürekli hale gelmesi ve daha sonraki kuşaklara aktarılması için bir aracı bulunması gerekmektedir. Bu aracılar bilerek ya da bilmeyerek geçmişten gelen özellikle de usta çırak ilişkisi içerisinde öğrendiği kültürü kendinden sonrakilere ya da başka kültü rlerdeki kişilere kendi bilgi hazinesindekileri farklı yollarla aktarmaya başlar. Gelenek aktarımında aracı, öğrendiği kültür üzerinde -bilinçli ya da bilinçsizce- bazı değişikliklere gidecektir. Bu değişikliklerde farklı etmenler vardır. Bunlar; teknolojik gelişim, küyerelleşme ${ }^{3}$, farklı kültürlerin birbirleriyle karşılaşması gibi etmenler. Aracılığın belli başlı görev ve amaçlarından "aktarmak/taşımak" bir kültürün kısmen ya da bütünüyle bir yerden bir yere taşınması biçimindeki mekansallığa ya da kültürel bellek alanlarında saklanarak geçmişten geleceğe aktarılması biçiminde zamansallı̆̆a vurgu yapar. Niğde düğünleri bu mekânlar için gösterilecek en güzel örnektir ve Niğde dügüncüleri birer kültürel aracı olarak geleneğin aktarılması ve sürekliliğinin sağlanmasında büyük öneme sahiptir. Dügünlerin ve aracı rol üstlenen müzisyenlerin incelenmesi geçmişin kaydının, kültürel mirasın belirli bir insan grubu arasında kimlik duygusu yaratma öneminin oluşumuna katkı sağlar.

Müzik bir olgu olarak, her toplumun, daha da indirgersek her bireyin yaşamında vardır. Her kültürün müzik geleneğinin var olduğundan söz edebiliriz, ama nasıl bir gelenek olduğunu sorgulamaya başladığımızda, seslerin düzenlenişinde ve içeriğinde farklılıklarla karşılaşırız (Kaplan, 2008: 21). Kültürel kimliklerin oluşması, değişmesi, anlamlanması gibi süreçlerde ise müzik aktif olarak rol oynar. Bu rol, toplumsal grupların bir değer yargısı ya da kültürel bir norm üzerinden birleşerek, bunları müzikal öğelerle yansıtmasıdır. Bu dişavurumla birlikte topluluk, kültürel kimlik oluşmasında temel nokta olan, farklı olma durumunu da müziksel öğelerle birlikte ortaya koyar. Bu sayede kültürel kimliklerini deneyimleyerek, hem yaşatır hem de yeniden anlamlandırırlar. Frith'de müzik yapmanın kültürel kimlikleri ifade etme değil yaşama biçimi

\footnotetext{
${ }^{3}$ Küreselleşme varlığını yerel dinamikler üzerine inşa eder. Kültür bağlamı küreselleşme tartışmalarında her iki olgu arasındaki ilişkiyi sorgulayan yaklaşımları beraberinde getirir. Küyereleşme kavramı, küresel (global) ve yerel (local) kelimelerinin iç içe geçen birlikteliğinin bir ürünüdür. Küyerelleşmenin ana düşüncesi, küresel ürünlerin yerel ihtiyaçlara göre düzenlenmesiyle birlikte, mal ve hizmetlerin oldukça farklılaşmış yerel ve özgün pazarlara, küresel veya küresele yakın bir temelde uyarlanmasıdır.
} 
olduğunu savunur (Yaltırık ve Kumpasoğlu, 2015, s.40). Kültürel aracılık, hem birbirine yabancı iki kültür arasında hem de aynı kültürün geçmişi ve bugünü arasında köprü kurar. Niğdeli müzisyen dügünlerde hem yeni popüler THM formunda beste eserlerin tanıtılması ve yayılması görevi hem de geçmişi günümüze bağlayan anonim THM türkülerini dügüülerde seslendirerek kültürel aracılık rolü üstlenmiş olur.

\section{Kültürel Aracı Olarak Niğdeli Müzisyenler}

Niğde dügünlerinde müzisyenlik yapan çalgıcıların yerli -Niğdeli ve çevre illerden- müzisyenler olması en önemli ve belirgin özelliğidir. Türkiye'de pek çok ilde dügünlerde Roman müzisyenler görev alırken, Niğde dügüunlerinde müzisyenlik yapan Roman sayısı yok denecek kadar azdır.

Niğdeli müzisyenler genellikle kendi bölgelerine hizmet ettikleri için iş teminlerini genellikle cep telefonu aracılığı ile yaparlar. Yaklaşık son 25 yıldan bu yana, düğünlerde müzisyenlik mesleğini usta-çırak ilişkisi içerisinde yapanların yanı sıra Niğde Üniversitesinde açılan 'Müzik Öğretmenliği" bölümünde okuyan ya da mezun olanlar da yörede bu mesleği profesyonel olarak sürdürmektedir. Bu nedenle, Niğdeli dügün müzisyenlerinin 'kültürel aracı' olarak konumlandırılması ayrı bir önem taşımaktadır. Her ne kadar, kültür ve uygarlık arasındaki çatışma, gelenek ve modernlik arasında sürmekte olan bir çekişmenin bir parçası (Eagleton, 2005, s.21) olsada, Niğdeli müzisyenlerin yaptıkları müzikal uygulamaları incelemenin diğer bir önemi ise geçmiş ile günümüz müzik uygulamaları arasındaki değişime odaklanarak, 'kültürel dönüşümün'ün ne oranda olduğunu tespit edebilmektir.

Türkiye'de Türk halk müziği ve arabesk müzik piyasasında aktif rol oynayan müzisyenler, piyasanın ihtiyacını karşılamak için sürekli değişik kaynaklardan yeni müziksel gereçler ve bu gereçleri farklı biçimlerde işleyebilecekleri seslendirme biçemleri ararlar. Bunun temel nedeni Türkiye'nin çok kültürlü yapısıdır. Bu durum Niğdeli müzisyenlerin formasyonunda da etkin rol oynar. Üstlendikleri bu rol ile anonim THM eserlerinde bazı değiş̧ikliklerin -bu değişiklik özellikle ritmik yapı ile ilgilidir- meydana gelmesine neden olur. Genç müzisyenler gele- 
neksel/kalıplaşmış dağarı eski müzisyenlerden öğrenirken, repetruvarlarında arabesk ve türk halk müziği eserlerde kendine yer edinir. Bu öğrenme genellikle usta çırak ilişkisi şeklinde yani birlikte gidilen işler sırasında yaşlı müzisyenin icrasını izleyip/dinleyerek olur. Böylece mesleğe yeni başlayan genç müzisyenler bir yandan dağarlarını genişletirken öte yandan farklı biçemlerde icra yapabilme becerilerini de geliştirmenin yollarını öğrenirler. Niğdeli müzisyenlerde, müzik yapmanın 'zanaat' olarak algılanması ve profesyonel müzisyenliğin ana amacı olan para kazanma, 'çalgıcılık' mesleğinin öğretildiği bir düğüncü çırağının eğitiminde de belirleyici bir rol oynar. Bu bağlamda Niğde dügüncülerinin müzikal kimliğinin temelinde var olan referans noktası anonim THM eserleridir. Söyledikleri türkülerin gerek form yapıları gerek ritimleri değişiklik gösterir fakat Orta Anadolu Türküleri referans noktasında daima kalıcıdır. Niğde dügünlerinde sabit nokta THM repertuvarıdır. Niğde ilinde, izler kitlenin bölgesel olarak farklılıklar göstermesine bağlı olarak düğün müzisyenliği de bölgesel ayrılıklara neden olmaktadır.

Enstrüman farklılıkları konusunda temel üç yönelme bulunmaktadır; elektro bağlama ve ritm/ ya da klavye, renk saz adı verilen keman, klarnet, cümbüş vs. ve bunların dışında davul-zurna. Niğde bölgesinde müzisyen düğünlerde 'ne istenirse onu çalarız' mantığ ile değil, bizim kültürümüzde 'bu türküler var bunları çalıyoruz' felsefesi ile hareket edilmektedir. Örneğin bir düğünde Trakya havalarını ancak bir kez o da hatıra binaen çaldırabilirsiniz (E. Bilen, kişisel görüşme). Düğ̈ünde müzisyene repertuvarında olmayan bir istek türkü gelmiş ise ve eğer dügün yaptığı dinler kitleye hitap edecek bir türkü ise bir sonraki düğüne kadar bu türküyü öğrenme zorundalığı hisseder. Türküleri ya internet aracılığ 1 ile dinler ya da nota okumayı biliyor ise notasını bulup öğrenir. Geçmiş yıllarda müzisyen bu işlemi ustasından öğrenerek ya da kasetçalarda dinleyerek yapıyordu (İ. Sancaktaroğlu, kişisel görüşme).

Müzisyen ve dinler kitle arasındaki iltişim Niğde ilinde Karanlıkdere köyünde önemli farklılıklar gösterir. Bu köyde düğüne gelen müzisyen, köydeki dinler kitlenin iyi bir THM dinleyicisi olduğunu bilir ve ayrıca burada gelen istek karşısında büyük bahşişler alacağını bildiği için gelen türkü isteğini mutlaka yerine getirir. Buraya gelen müzisyen şunu bilir; seslendirme ne amaçl yapılırsa yapılsın istenilen, başka bir deyişle sipariş edilen türkü geri dönemez, icra edilmek zorundadır. Burada istenilen her eserin parasal 
bir anlamı-maddi bir karşıllŭg-vardır. Çünkü türküler söylendikçe, paralarda dökülmeye başlar. Karanlıkdereye müzisyenlik yapmak için gelen kişiler stratejik olarak para kazanma ekseninde bu faktörleri gözönünde bulundurur. Bu nedenle müziğin paraya dönüştürülmesi ile ilişkili kolektif davranışlar sergilerler.

Niğdeli müzisyenlerin küyerelleşme aracılığı ile özellikle çevre illerde -ki bunların başında Ankara havaları gelir- söylenilen yeni bestelenmiş, ya da düzenlenmiş türküler belirli bir süre içerisinde öğrenmesi gereken bir hal alır. Kültürel olarak birbirine çok yakın özellikler sergileyen bu bölgede türkülerin yayılma hızı da oldukça hızlı gerçekleşir. Her ne kadar bu yeni eserler söz konusu olsa da düğün boyunca özellikle hareketli türkülerin dışında yeni bestelenmiş -türkü formunda beste- eserler tercih edilmemektedir. Genellikle hareketli yeni türküler, ya da geçmiş yıllarda meşhur olmuş fakat sözleri değiştirilmiş -Oy gelin Oy damat (Burhan Çaçan'ın kasetinde 'Oy Nene' adıyla okuduğu türkü) gibi- türküler tercih edilmektedir. Niğdeli müzisyenlerin kültürel aracılıkları, yalnızca iki kültür arasında değil çoğu zaman aynı anda birçok kültür arasında aracılık etmek üzerine kuruludur. Bu nedenle müzisyenlerin aracılıkları iki kültürlü değil çok kültürlüdür. Aracılıkla ilişkili kültürel rolleri ve konumları tarihsel, kültürel ve ekonomik nedenlere bağlı olarak önceden belirlenmiş olup geçici değil kalıcıdır. Niğdeli düğün müzisyen kimliği, yalnızca bir düğüncü grubu değil aynı zamanda kurumsal bir kültürel aracılık kimliğini tanımlar. Aracılık rolleri çoğu zaman bireysel değil işbirliğine dayalı kolektif bir aracılık olarak görülmelidir (Yükselsin, 2014, s. 729). Niğde düğünlerinde müzisyenlik yapan ve diğer müzisyenlere görece en 'beceriksiz' olanı bile bu işbirliğine katkıda bulunur ve yeri geldiğinde aracılık rolünü sırtlanır.

\section{Niğde Düğün Kültürüne Genel Bir Bakış}

Toplumsal kümeyi oluşturan insanların sürekli yer değiştirdiğini, bu çerçevede üretilen ve gelecek kuşaklara aktarılan bu sözlü geleneğin zaman içinde yazı/nota kullanabildiğini ve en önemlisi halk müziği dediğimiz bu birbirinden farklı somut toplumsallıkların homojen olmayan müziklerinin, kendisinden eğitim-öğretim ve aktarım modelleri ile müziksel özellikleri açısından farklı geleneklerle (sanat, popüler müzik 
vb.) yüzyıllardır alışveriş halinde olduğunu belirtmek gerekir (Erol, 2009, s. 72). Çalışma konumuz olan Niğde yöresindeki müzisyenler, yöredeki müzikal kültürün sürekliliğini dügünlerde türküler söyleyerek sağlamaktadırlar. Dügün, tüm dünya kültürlerinde olduğu gibi Türk kültüründe de insanların mutluluklarını ifade eden törenler arasındadır. Her kültür, düğünü kendi kural ve kalıplarına uygun olarak gerçekleştirir (Altun, 2004, s.92). Bugüne kadar düğünlerin yapısını etkileyen ve eski ile yeniyi buluşturan ritüel hareketleri ile ilgili kaynaşmalar hakkında çok az çalışma yapılmıştır. Dügün ritüellerinin çeşitli aşamalarında geçen bu ritüel ve kaynaşmalar, ne yazık ki ülkemizin pek çok yerinde kaybolmaya yüz tutmuş ve pek çoğu da ortadan kalkmıştır. Niğde ili bu yok olmanın en az yaşandığı yerlerden birisi olarak ayrı bir önem taşımaktadır. Sanayileşmenin azlığı, büyükşehir statüsünü almamış olması ve köy/şehir kavramının belirli oranlarda halen devam ediyor olması geleneksel dügünlerin sürekliliğinde önem taşımaktadır.

Niğde düğünlerini belirli kodlar üzerinden gruplara ayırmak gerekir. $\mathrm{Bu}$ gruplamalarda evlilik ritüellerinde yapılan uygulama farklılıkları temel belirleyici faktör olmaktadır. Her ne kadar yüz ölçümü olarak küçük denilebilecek bir alana sahip olsa da kültürel farklılıklar ve normatif kodlama farklılıkları bu ayrımı belirginleştirir. Törenler toplumsal bir gerçekliğe işaret eder: Yetişkin erkeklerin ayrıcalıkları kadınlarınkinden çok daha fazladır (Benedict, 2011, s.56). Gelenekselleşmiş davranış kodları içerisinde önceden belirlenmiş çeşitli aşamalara sahip olan bu düğünler, kadın merkezli, erkek merkezli ve kadın erkek merkezli olarak 3'e ayrılabilir. Bu ayrımlardan dolayıdır ki dügünlere genellikle iki ayrı müzisyen grubu dügün için kiralanır. Son yıllarda bu durum iki ayrı müzisyen grubu kiralamak yerine teknoloji yardımıla ses sisteminin bir tanesini kadınların oturduğu mekana kurulmasıyla farklı bir uygulama yapılmaya başlanmıştır. Ekonomik durumu iyi olan düğün sahipleri bu durumda genellikle iki ayrı grup kiralamayı hatta bir tanesinin kadın müzisyen olması konusunda oldukça ısrarlı olmaktadır. Fertek ve çevresinde ise klasik saz grubu ve anonim saz grubu olarak iki ayrı grup daha fazla tercih edilmektedir.

Dügünlerde dinler kitle farklı kültürel kökenlere sahip olsa bile ya kız tarafı ya da erkek tarafının Niğde'li olması işi kolaylaştırır. Bu ortamda kişisel beğeniler bir yana bırakılarak yöreye ait ezgiler çalınır. Başka bir 
şehirden gelen dinler kitle misafirler çalınan türkülerin pek çoğuna kulak aşinalığı yaşadığı için büyük bir problem meydana gelmez. Hatta popüler kültür ürünü küyerelleşme aracıllı̆ıyla ortaya çıkan yeni eserler (örneğin Çilli Bom gibi) büyük bir tepki ile karşılanmaz. Her ne kadar çok kültürlü bir toplum örneği göstermese de Niğde ve çevresinde bölgesel/kültürel ayrilıklar müzisyenlerin de bu anlamda ayrılmasına neden olmaktadır. Kendi bölgesinin dışında düğün çalmaya giden müzisyen bu işi ya zorda kaldığ kimse kendi bölgesi dışında müzik yapmak istemez. Böyle bir zorundalık yaşamaları durumunda ilk iş olarak o bölgeyi çok iyi bilen bir müzisyen arkadaşını arayarak ön bilgi aldıktan sonra düğüne gider.

Niğde köy düğünlerinin en yaygın enstrumanı bağlamadır. Davul zurna kültürü sadece Adana'ya yakın olan ve özellikle yaz aylarında büyük oranda Adana'dan göç alan Çamardı ve Ulukışla ilçelerinde yaygındır. Bağlama ve davul/zurna kültürü dışında Niğde'ye bağlı Fertek/Koyunlu bölgesinde klarnet, darbuka, keman, cümbüş gibi enstrümanlar kullanılmaktadır. Dügünlerdeki oyunlar da çok çeşitlidir. Bunlar her yöreye göre değişen halk danslarıdır. Halay, her yörede ortak olan biçimidir. Niğde bölgesinde halaylara Çamardı ve Çiftlik civarında rastlanmaktadır. Fakat, Niğde merkez, Bor ve çevresinde halay kültürü yok denecek kadar azdır. Dügüülerde tüm bunların dışında seyirlik oyunları, çeşitli yarışmalar, komiklikler de köy düğünlerimizin ortak özellikleridir. Bu gelenekler Niğde ve çevresinde halen yaygın olarak devam etmektedir. Bunun nedeni ise; sokak dügüülerinin sürekliliği, düğünlerde halen türkülerin söyleniyor olmasıdır. Niğde düğünlerinde görev alan müzisenler dügünlerde söyledikleri türküleri şu yollarla öğrenmektedirler; usta çırak ilişkisi ile, kaset/cd/internet yoluyla, uydu üzerinden yayıyan yapan Tv kanalları (Seymen TV/Vatan TV. vb.) sayesinde ve son yıllarda TRT repertuvarındaki türküleri solfej yaparak (genellikle, Üniversitelerin müzik bölümlerinden mezun müzisyenler). Sürekli güncellenen dağarın saklandığı bellek, bekraundunda sakladığı türküler ile birlikte bir "depo" gibidir.

Niğde düğünlerinde meydana gelen değişikliklerleri yöre müzisyenlerinden Bilen "Düğünlerde müzisyen çalar söyler, düğüne gelenler oturup sadece dinlerdi, dügünlerde içkiler içilir sadece belirli kişiler oynard1. 2000'li yıllardan sonra içki giderek azaldı. Keçikalesindeki 
dügünlerde hiç oyun olmazdı, oturak âlemi gibiydi. Düğünler sabahlara kadar devam ederdi, Cuma namazından sonra başlar Pazar akşamına devam ederdi. Halk arasındaki espride İbrahim Tatlıses 2 saat sahnede kalsa rekor sayılır oysaki Niğde müzisyenleri 3 gün durmaksızın düğün yaparak asıl rekoru kırıyordu (E, Bilen, kişisel görüşme)" şeklinde belirtmiştir.

2000 yılına kadar pek çok köyde dügün müzisyenliği yapan Sancaktaroğlu, Niğde köy dügünleri hakkında genel olarak şunları söylemiştir: "Dügüünler en az 3 gün en fazla 1 hafta sürerdi. Akülü cihazlar çıkıncaya kadar enstrümanlar kuru çalınırdı. Ekonomik durumu iyi olanlar takım çalgı tutardı -klarnet, cümbüş, keman-, diğerleri ise dügüunler için bağlama tutardı. Dügünde erkekler ile kadınlar arasına ip gerilir ipin üzerine savan gerilirdi kadın ve erkekler birbirini görmezdi. Dügün süresi içerisinde sadece belirli zamanlarda oyun olurdu, masalar kurulur içkiler içilirdi. Dügünden ziyade bir konser ortamı oluşurdu. Gelin, bayanların olduğu bölgede damat, erkeklerin olduğu bölgede olurdu. Gelin ağlatmada kadınlar arasında bir ağıt söylenilir kına yakılırdı. Eskiden yöremizde dügüülerde genellikle uzun hava yada kırık havalar çok meşhurdu, oyun havaları çok çalınmazdı. Kadınlar erkeklerin görmediği yerde kendi aralarında 'kara tef ${ }^{4}$ ' ile eğlenirlerdi. Tef'i ya köyden bir kadın ya da müzisyenin yanında getirdiği çocuk yaştaki oğlu yada çırağı çalard1 (İ. Sancaktaroğlu, kişisel görüşme).

Niğde dügünlerinde elektro bağlama yaklaşık 1980'li yıllarda kullanılmaya başlanmıştır. Bor dışında müzisyenlik yapanlar bu tarihten sonra bağlamalara 'nesli' takmaya başladı. Yaygınlaşmaya başladıktan sora biz 'nesli' kullanmadığımız için çaldığımız düğünlerde 'sen çalamıyorsun' gibi sözler söylenmeye başlandı (E. Bilen, kişisel görüşme). Yörede davul zurna kültürü olmadığı için bağlamaya ayrı bir önem verilmiştir.

Yöredeki düğün müzisyenleri yaptığı işi o kadar çok önemser ki, önceki yıl çaldığı repertuvarda bir sonraki yıl belirli değişiklikler yaparak dinler kitlenin sıkılmasını önlemeye çalıyır. Önceki yıl Neşet Ertaş türkülerini ağırlıklı olarak çalmış ise bir sonraki yıl Mahsuni Şerif vb. sanatçıların türkülerine öncelik verir. Özellikle Bor ve çevresinde, Mahsuni

\footnotetext{
${ }^{4}$ Soğuk havalarda tef'in derisini ısıtmak için ocakta yada gazete yakarak deri ısıtılır, bu işlem sırasında tef is olur ve rengi sihaya dönerdi, bu nedenle adı 'kara tef' olmuştur.
} 
Şerif türküleri dügünlerde sıklıkla çalınmaktadır. Mahsuni Şerif türkülerinin çalınmasında herhangi bir siyasi uyanış düşüncesinden ziyade hareketli olması hatta düğün müzisyeni tarafından orijinal ritminden daha da hızlı çalınması bölgede sevilmesini sağlamıştır. Türkünün sözlerindeki sosyal ve siyasi içerik dinleyenler tarafından dikkate alınmamaktadır. $\mathrm{Bu}$ türküleri dügünlerde gelen istekler ile öğrenmek zorunda kalıyordum. Âşık Mahsuni Şerif Eserleri; Ha babam Ha, Fırıldak adam, dilaver, Han sarhoş, leylim ley, Mamudo gurban (H. B. Arık, kişisel görüşme).

Yörede çoğunlukla okunan türküler; Sarı yıldız, Saffet effendi, Atım araptır, Hüdayda, Çakmak çakmağa geldim, Cezayir türküsü (kalk gidelim havası), Halime giz, Abaruh, Haydi bizim evde şeker lokum, Yine yeşillendi fındık dalları, Kendisi ufacık, Cimdallı çarşısı, Yaban elleri, Ceviz oynamaya geldim odana, Niğde bağları, Aslan Mustafam, Konyalım, Develi (kaşık oyunu), Cubuk Uzun, Sille, Sazalcadan çıtım, Çubuk benim tel benim, Eşme kaya dedikleri, Mapushaneye attım postumu, Allılar, Kara kız, Keşke gelmeseydim yalan dünyaya, yazı bir dert, şu yüce dağların karı eridi, Su ver leylam, Naciyem (Bor'da milli mars gibidir). Uzun havalar; Yiğidin bindiği, Gelin Cafiyem, Küçükten görmedim ana kucağı, Yüklendi çeyizim gidiyor göçüm.

\section{Çamardı, Ulukışla, Melendiz ve Çiftlik}

Çamard1/Bademdere/Üçkapılı bölgesi, Adana-Tarsus-Mersin yöresi kültürünün ağırlıklı görüldüğü yerlerdir. Yöre Adana-Mersin'den gelen yaylacıların uğrak yeri olduğu için yaylacılardan etkilenilmiş ve kültürler birbirine karışmıştır. Dügünlerde özellikle Adana yöresi türküleri (Adana köprü başı gibi) bol miktarda çalınıp söylenir. Bu yöredeki düğünler müzisyenlerin "tek gecelik işler" diye tanımladığı Cumartesi akşam başlayan ve Pazar günü öğle saatlerinde sona eren dügüülerdir. Dügünlerde eskiden içki içildiği fakat günümüzde düğünlerde içkinin yok denecek kadar az olduğu müzisyenler tarafından belirtilmiştir. Yörede dügünler kır düğünü şeklinde bahçede yapılır. Kış günlerinde düğün sayısı yok denecek kadar azdır. Düğün yapılacağı zamanlarda ise gündüz yine dışarıda gece köy odasında devam edilir. Yöreyi diğer Niğde düğünlerinden ayıran özellik davul-zurna kültürüne bağlı olarak dügünlerde halay'ın yaygın olmasıdır. Düğünlerde genellikle Neşet Ertaş türküleri 
söylenir. Yörede dügün müzisyenliği yapan müzisyenler bu konuda şunları söylemişlerdir; "Küçük yaştan bu yana kulağımızda bulunan ezgiler Neşet türküleridir. Bu bölgedeki herkes, babadan, dededen, müzisyenlerden en çok dinlediği kişi Neşet Ertaş'tır. Ezgilerin kulağımızda olması çalınmasını da kolaylaştırıyor. Bor ve çevresindeki düğünlerde sabahlama olayları var, 3 gün boyunca çalarsınız. Fakat Melendiz ve çevre köylerinde gece 11-12 gibi dügünler sona ererer (O. Ersin ve N. Güngör, kişisel görüşme)". Yöredeki yaşlılar kendi bölgelerinde de dügüülerin eskiden sabaha kadar devam ettiğini ve içki içildiğini, fakat günümüzde bu tür uygulamaların yapılmadığını belirtmiş̧lerdir.

Yöredeki müzisyenler yaptıkları işin zorluğu ile ilgili olarak şunları söylemişlerdir; "Bu bölgedeki düğün kültürünü diğer bölge müzisyenleri kaldıramaz, bu bölgede cihazı kurup/dağıtma vardır. Cumartesi sabah oğlan evine kurarsın, öğleden sonra kız evine daha sonra yeniden Pazar sabahı oğlan evine cihaz kurarsın. Bu işin zorluğunu bor tarafı müzisyenleri çekmezler. Sabah oğlan evinde cihazı kurarsın öğleden sonra cihazı oradan toplayıp kız evine cihaz kurarsın. Bor ve çevresinde böyle bir uygulama yok, cihazı kurarsın 3 gün boyunca cihaz orada kurulu kalır. Bizim yörede sürekli halay çekilir ve oyun oynanır. Bu yörede halay denildiği zaman köylünün 7 'den $70^{\prime}$ e herkesi halayda görebilirsiniz. Yöredeki dügün kültüründeki en büyük özellik, müzisyen ya o bölgenin çocuğu olduğu için köylünün ne istediğini biliyor, ya da bilmediği bir köy ise o köyde daha önce çalan dügüncülerden köy kültürü hakkında bilgi alıyor (E. Orhan-İ. Coşkun, kişisel görüşme)".

Yöredeki halaylar: 3 ayak; halebi, kırıkhan, peşkir çektim, arzu-kamber (helkemi suya daldırdım) Yılan aktı kamışa. 2 ayak; Kostak yörü yörü (Bor yöresinde bu türküye hızlı ritmde oyun oynarlar), arkasından "Sekme" adı verilen oyunlar; caney, lorke, ha babam ha, nare, toycular, çekin halay dizilsin, karayer kara yerde ardından sekme yani; Cimdallı çarşısı başlar. Yani, üçayak, iki ayak ve sekme devam eder sekmeden sonra kürt halayları ile bitirilir; caney caney-lorke, parmağında yüzükler, kız ben sana demedimmi karşıki dağlar cenderme, ha babam ha ritim giderek hızlanır. Ha babam ha ${ }^{5}$ ezgisinin bölgede farklı bir özelliği vardır; Çamardı, Çiftlik bölgelerinde bu türküye halay çekilir iken, Bor ve çevresi

${ }^{5}$ Âşık Mahsuni Şerif'e ait bir türküdür. 
gibi halay kültürünün yaygın olmadığı bölgede hızlı ritmde (120 metronomda-Allegro) 'gelenek icadı' bir oyun sergilenir. Yörede düğ̈̈nlerde köyler arasında da halaylarda farkılılıklar görülür. Örneğin; Murtaza köyünde iki ayak halayı çekilmez. Hangi köyde hangi halayların çalanacağını ya müzisyen zaten bilir ya da halay başı eliyle müzisyene işaret eder. Doğal olarak müzisyenlerin de repertuvarları gittikleri yere göre değişir. Yörede Misket, Fidayda, gibi Ankara yöresi türküler yaygın olarak söylenir.

\section{Fertek, Koyunlu, Fesleğen, Hançerli}

Yörede "takım çalgılince saz" adı verilen Cümbüş, Klarnet, Keman ve ritm enstrümanlarının yaygın kullanıldığı dügünler yaygındır. 2000'li yıllardan sonra 'sazcı' adı verilen elektro bağlama-klavye müzisyenler de düğünlere davet edimeye başlanmıştır. Fertek kasabası ve civarındaki düğünler genellikle erkekler tarafından içkili/eğlenceli gerçekleşir. Niğde ve civar illerin türkülerinin seslendirildiği yöre dügünlerinde, kadınlar evin önünde kendilerine ayrılan bölgede eğlenirlerken, erkekler ya boş patates ambarlarında ya da dışarıda kadınlardan ayrı bir yerde eğlenirler. Erkekler takım çalgı ile eğlenirken kadınlar elektro bağlama ve darbuka eşliğinde eğlenirler. Yörede düğünler Cuma sabah saat 09:00 civarı başlar Pazar günü saat 14:00 gibi sona erer. Gece geç saatlerde yaklaşık 3-4 saatlik dinlenmenin dışında bu sürenin tamamında müzisyen çalmaya devam eder.

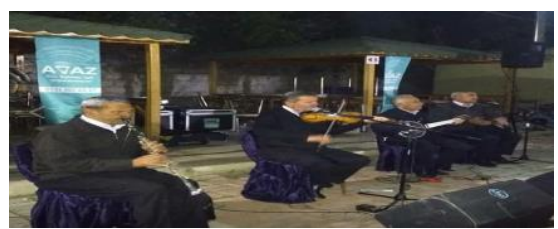

Resim 1: Bor ve Çevresinde müzik yapan Renk saz ekibi.

Yörede meşhur "takım çalgı" müzisyenleri şunlardır; Cavit Kılıç (Cümbüş)'ın ekibi, Keman: Halil Amca, Cavit Öztelli, Klarnet: Fedai Aslan, Kemal Menteş, Nevzat Yaşar ve Cevdet bey (lakabı Patriyot), Ud: Hacı Emin, Darbuka: Recep Adıyaman (N. Yaşar, kişisel görüşme). 


\section{Bor ve Çevresi}

Bor ve çevresinde düğünler cuma günü, cuma namazı sonrasında başlar ve 3 gün durmaksızın (günümüzde biraz daha esnetilerek, sabah saat 09:00'da başlar) devam eder. Çay servisi, yemek dağıtımı ve düğün esnasında ortaya atılan para (bahşiş, alatura) organizasyonları için 'çavuş' adı verilen 2-3 kişi görevlendirilir. Sabahın erken saatlerinde çalmaya başlayan müzisyen namaz saati ve akabindeki yemek saatinde dinlenir. Düğün davetlileri namaz sonrasında dügün evinde sofrada buluşur ve imam önce kazan duası gerçekleştirir ardından yemek dağıtımı yapılır. Daha sonra beybaşı derlemesi yapılır. Ardından yöresel kıyafetler giyen başında üç renk (sarı, kırmızı, yeşi1 ${ }^{6}$ ) gül takılı olan düğünün yengesi ${ }^{7}$ sırtına bir heybe atar, heybenin gözünün bir tanesinde kavurga (ekmek sacının içerisinde kavrulan buğday yada arpa) vardır, diğer gözünde de üzüm ve leblebi vardır. Bu gelenek yörük topluluklarının eski dügün geleneklerindendir. Yemek yenildikten sonra damat, sağdıç ve arkadaşları dügüne gelmiş ve oyuna kalkmamış misafirleri tek tek anons ettirerek oynamaya kaldırır. Burada en dikkat çekici durum, müzisyenlerin yanına köyü iyi tanıyan çavuşlardan bir tanesi oturur ve oynamaya kimi çağıracağ 1 konusu ile ilgili müzisyeni o yönlendirir. Bu eğlencenin büyük bir çoğunluğu erkek erkeğe yapılır. Kadınlar yaklaşık 50 metre kadar yakın bir yerde bir halka oluşturarak kendi aralarında oynarlar. Müzisyen hoparlörleri onların da duyacağı bir şekilde yerleştirir. Elektronik cihazların yaygın olmadığı yıllarda yörede tanınan bağlama çalan Cemal adlı görme engelli bir müzisyen yanında darbuka çalan bir erkek çocuk ile birlikte kadınların olduğu bölümde müzisyenlik yapardı (S. O. Sarıteke, kişisel görüşme). Yine aynı yörede "Defçi Sultan” kadınların olduğu bölümde müzisyenlik yapardı (S. Ş. Eriç, kişisel görüşme).

İkindi namazı vakti kız tarafına haber gönderilir ve kına yakılır. Müzisyen bu arada gelin evine cihazlarını götürüp oraya kurar. Kızın birinci derece yakınları ilk olarak oyuna davet edilir, ardından damadın ailesi oynar. Burada söylenilen türkülerin ritmik yapısı daha hızlıdır. Örneğin, 'çubuk uzun' türküsü 90 metronomda (Andante) iken kız evinde

\footnotetext{
${ }^{6}$ Bu geleneğin Ortaasya Türklerine ait halen günümüze kadar devam eden bir gelenek olduğunu düşünmekteyiz.

${ }^{7}$ Dügüün sahibinin en büyük gelini ya da dügünü organize edecek hala ya da teyzelerden bir tanesi.
} 
110-120 metronomda (moderato) söylenilir. Burada söylenilen diğer türküler şunladır; 'tepeciğin heliğ $i^{8}$, mısırlar saçak saçak, yaban ellerini, al kayadan at bani, alim amman amman, cimdall çarşısl, sarı yıldır, pınara gel ki görem, hasanım olurmu böyle (Uluören ve Karakapı köylerinde uzun hava olarak söylenilir $\left.{ }^{9}\right)$ türküleridir.

Kına hazır olduğu zaman kız evinden müzisyenlere "hoca $a^{10} k ı n a$ havasını vur" diye seslenilir ve müzisyenler "kınayı getir aney ve çakmak çakmă̆a geldik" türküleri seslendirilir. Bu bölgede kına töreninde diğer yörelerde meşhur olan "yüksek yüksek tepelere ev kurmasınlar" türküsü seslendirilmez. Gelinin eline kına yakılırken yörede çok meşhur olan "ă̆g gelinde indim ola yayladan" uzun havası mutlaka okunur. Sadece kına yakımından sonra çok kısa süreli doğu Anadolu yöresinden halay türküleri olan "caney caney ve lorke" çalınır fakat buna halay çekilmez karşılıklı oyun oynanır. Yörede davul zurna kültürü yoktur. Yöre kültüründe geçmişi çok eski olmayan "gelenek icadı" olarak tanımlayabileceğimiz "testi oyunu" adlı bir oyun sergilenir ve bu oyun esnasında "oy gelin oy damat" eski adı "damdan dama damımız yakındır eyvanımız" türküsü seslendirilir ${ }^{11}$. Yöre düğünlerinde ezgiler çok yüksek tempo ile çalınıp oynandığı için yarım saatte bir müzisyenler mola vermek zorundadır. Kına faslının sonunda düğüncülere aşçların yaptığg yemekten yemek gelir. Akşam yemeğinden sonra insanlar toplanıncaya kadar, uzun hava ve hareketli olmayan kırık hava türküler çalınır.

Dügünler hangi mevsimde yapılırsa yapılsın mutlaka dışarıda (sokak düğünü) yapılır. Fakat Uluören, Karanlıkdere gibi köylerde düğünler genellikle bayram günlerinde olur. Çünkü; köylülerin büyük çoğunluğu İstanbul, Ankara vb. büyük şehirlerde hurdacılık işi ile uğraşır. Bayramın 4. günü en son düğünü bitirirler ertesi gün İstanbul'a döner ve işe başlarlar. Bayramlarda yapılan dügünler ile ilgili olarak S. O. Sarıteke şunları söylemiştir; bu köylerde, kurbanın birinci günü düğün çalmaya bir başlardık 15-20 gün köyün içerisinde devamlı düğün çalardık, sabah git

\footnotetext{
${ }^{8}$ Türkünün beyitleri çok fazla olduğu için gün içerisinde pek çok kez söylenilir.

${ }^{9}$ S. O. Sarıteke bu türküyü bölgenin eski müzisyenlerinden Oruç beyden öğrendiğini belirtmiştir.

${ }^{10}$ Son yıllarda yörede pekçok müzik öğretmeni, aynı zamanda düğ̈̈n müzisyenliği de yapmaktadır. Bu nedenle müzisyene 'hoca' tanımlaması kullanılır.

${ }^{11}$ Türkünün orijinali Burhan Çaçan tarafından 1990'lı yıllarda söylenmiştir.
} 
akşam gel. Bazı düğünlerde, özellikle cumartesi günü düğün sabaha kadar devam ederdi, çevrenin rahatsız olacağı bir durum olur ise düğün gece 12'den sonra bağ evlerinde (Bağdüzü, Aliyer, Sivrikise, Sazala, Bulgarcık taraflarında) sabaha kadar devam ederdi. Fakat, son yıllarda saat 24:00 gibi sona erer. (S.O. Sarıteke, kişisel görüşme). Günümüzde düğün süresinin kısalmasının nedenlerinin şunlar olduğunu düşünmekteyiz; Birincisi, yatılı misafir kültürünün giderek azalmasından dolayı düğün bitiminde herkesin evine yola çıkmak istemesi, ikincisi dügüunlerde içki tüketinimin giderek ortadan kalkmasından kaynaklanmaktadır.

Yörede köyden köye bazı farklılıklarda gözlemlenmektedir. Örneğin; Asmaz (Yeşilyurt eski adı) Ekrem Aydostlu'nun “Ötmesin Bülbüllerde solmuştur gülüm" uzun havasını bilmiyorsanız bu köyde düğün çalamazsınız. "Yaban ellerine" adlı türküye Melendiz ve çevresinde halay çekilirken aynı türküye Eskigümüş düğünlerinde halay çekilmez. Mahsuni Şerif Dilaver türküsü düğünün olmazsa olması gibidir (M. Dağlı, kişisel görüşme).

Yörede "Beybaşı derlemesi yada Beybuğ" denilen bir ritüel gerçekleştirilmektedir. Sabah saat 08:00 civarı başlayan düğünde öğle saatlerine kadar uzun hava (Erken düşer şeker dağın gırcısıdır, Yavru şahin enginlerde kışlamaz, Gönül dağı bozlakları mutlaka okunur) ve ağır ritimli kırık havalar çalınır. Saat 11:00 civarı müzisyen mikrofondan 'beybaşı derlenecektir' diye anons yapar. Dügün meydanında damat ortada olacak şekilde tüm davetliler damadın etrafında çember oluşturur ve damadın önünde bulunan kutu'ya herkes küçük meblağlarda para atar. Bu para düğün boyunca yapılacak -çay, bisküvi, şeker vs.- masrafların karşılanması için kullanılır. Beybaşı derlemesinin ardından müzisyen ritmik yapısı çok hızlı türküler çalarak, düğünün artık yavaş yavaş daha eğlenceli hale gelmesi 'yani hareketli eserlere' geçilmesi gerektiğini anlar. Beybaşı derlemesinden sonra damat ve sadıç karşılıklı olarak Naciye, tepeciğin heliği, hasanım, oğlan oğlan türküleri ile oynatılır.

\section{Muhactrlar}

1923-1924 yılında Yunanistan ile yapılan antlaşma sonucunda Türkiye'ye göç eden mübadiller yörede ilk olarak Bor ve çevresine (yukarı sokubaşı 
ve aşağ1 sokubaşı mahalleleri ${ }^{12}$ ) daha sonra ise Kavuklu, Aktaş, Hasaköy, Konaklı kasabalarına yerleştirilmişlerdir. Kendilerini "Selanik göçmeni" olarak isimlendiren bu topluluk düğünlerinde genellikle Bor dügün kültürünün neredeyse aynısını gerçekleştirirler. Fakat halay kültürünün görülmediği Bor'da yaşayan muhacırlar "Malatya, Caney ve Lorke" türkülerine halay çekerler. Önemli farklardan bir tanesi dügünde mutlaka "Çanakkale içinde aynalı çarşı" türküsüne topluca halay çekerler. Muhacırlar Selanik göçmenidirler ve Atatürk ile her zaman gurur duyduklarına hatta Atatürk'ü akrabaları olarak gördüklerini belirtirler. Atatürk'ün hem akrabası hemde komşusuyuz (K. Özdamar, kişisel görüşme).

Dügünler genellikle Cuma günü başlar ve Pazar günü gelin alma ile sona erer. Düğünlerde Üryan (Yunanca adıyla Micloris) adını verdikleri etli pilav mutlaka yapılır. Düğünlere 'hacı takımı' adını verdikleri renk sazlar mutlaka davet edilir. Renk saz ekibi Niğde'den gelir. Eskiden dügünler mutlaka evin avlusunda yapılırdı. Fakat, 1990'lı yıllardan sonar salon kültürü yaygınlaşmaya başladı ve artık düğünler salonda yapılmaktadır. Salon dügünleri ile birlikte elektro bağlama ve ritm muhacır düğünlerine dahil olmaya başlamıştır. Muhacır düğünün kültürel özelliklerinden bir tanesi 'Çanakkale' türküsüne halay çekilmesi, diğeri ise gayda adını verdikleri bir müzikli ritüeldir.

Gayda; düğüne katılan ileri yaşlardaki davetliler alanda toplanır ve hep bir ağızdan sözsüz olarak mırıldanma ezgisiyle ağıta benzer bir ezgiyle halay çekerler. Bu halay eğlenceden çok topluluğun göç yollarında kaybettiklerini andıkları, hafıza tazeledikleri bir ritüeldir. Gayda bittikten sonra hep birlikte halay çekilir. Elektro bağlama düğünlerine dahil olmadan önce Trakya bölgesi ezgileriyle halay çeken muhacırlar, günümüzde yaygın Anadolu halay türküleri ile halay çekip türküler söylemektedirler. Görüşme yaptığımız muhacırlara gayda'yı neden kapalı ağızla söylediklerini sorduğumuz zaman; bu ezgileri müzisyenler bilmezdi, sadece yaşlıların hafızalarındaki ezgiler söylenirdi" şeklinde belirtmişlerdir.

\footnotetext{
${ }^{12}$ Bor'da Yukarı Sokubaşı (Bordaki kilise ve çevresi) ve Prapaska (sebze pazarının olduğu yer/yerliler Aşağı Sokubaşı derler, fakat bizler Prapaska deriz). Sadece Yukarı Sokubaşı Arnavutça konuşur fakat Aşağı Sokubaşında yaşayanlar bunu bilmezler.
} 


\section{Sonuç}

Sanayileşme ve kentleşme sürecinde yaşanan değişimlere bağlı olarak, Türk milli kültürümüzde yaşanan değişmeler düğünlerimize de yansımaktadır. Tüm bu etmenlere bağlı olarak 'salon dügüun'leri köylerimize kadar girmektedir. Geleneğin sürekliliği konusunda hassas olan ve kültürel bağlarına bağını sürdürmeye çalışan bazı yörelerimizde düğün geleneklerinin özünün kaybolmaması için büyük özen gösterilmektedir. Bu özenin gösterildiği şehirlerinden bir tanesi de Niğde ilidir. Niğde ili dügüunleri geleneğin sürekliliği ve kültürel mirasın aktarımında büyük önem taşımaktadır. Sınırlılıkları net çizgilerle belirlenememekle birlikte Niğde yöresi düğünleri, teorik uygulama farklılığına göre davul-zurna enstrümanı ile 'halay' odaklı düğünler, renk saz enstrümanları (klarnet, cümbüş, keman vb.) odaklı dügünler ve elektro bağlama-klavye enstrümanı odaklı dügünler olarak 3'e ayrılabilmek mümkündür.

Niğde düğün müzisyenleri etik ve emik çerçevede 'düğüncü' olarak tanımlanmaktadır. Müzisyen olmanın yanı sıra 'Türk kimliği'de müzisyenin vazgeçilmez bir parçasıdır. Niğdeli müzisyenler, diğer mesleklerle tanımlanan birçok alt gruptan kendilerini ayırarak farklı konumlandırmaktadır. Bu konumlandırmanın getirisi olarak da müzisyenler 'kültürel aktarıcı' olarak tanımlanabilir. Gelişen teknoloji nedeniyle bir zamanlar yaklaşık 3 ila 6 kişi arasında gidilen düğün müzisyen sayısı günümüzde 1 kişiye kadar düşmüştür. Düğünlere tek başına giden müzisyen klavyeden ritm ve alt yapı sesler kullanırken elindeki elektro bağlama ile ana ezgiyi çalar ve türküleri okur. Yörede kültürel farklılıklar müzisyenler arasında da farkl1lıklar oluşmasına neden olmuştur. Yaklaşık $2.302 \mathrm{~km}$ kare alana sahip olan bölgenin yukarıdaki üç faktöre göre kendine özgü müzisyenleri vardır. Coğrafi olarak bakıldığı zaman Niğde ilinin doğusunda bulunan köylerde ritmik yapı daha ağır iken batı bölgesindeki köylerde ritmik yapa daha da hızlıdır. Niğde'nin batı bölgesindeki ilçelerde -Bor ve sonrası- ritmik yapının giderek hızlanması türkülerin orijinal yapısını bozmaktadır. Dügünlerde söylenilen türkülerin ritmik yapısında meydana gelen değişime bağlı olarak, düğün örf ve adetlerinin etkisi azalmaya başlamış, düğünler yeni ve daha hızlı ritmik yapısıyla toplumun alışılmış değerlerini zorlayarak büyük oranda değişime neden olmuştur.

Yörede çalışan müzisyenler genellikle hitap ettikleri kendi çevresi tarafından düğüne çağrılır. Fakat bayram dönemleri gibi özel zamanlarda 
düğünlerin yoğun olmasından dolayı Niğde ili içerisindeki farklı bölgeye düğünlere davet edilebilmektedir. Niğde düğünleri ve düğünlerde müzisyenlik yapanlar kültürel aracılığın birkaç amacını yerine getirmektedirler. Bunlardan birincisi yerel müziklerin dügünlerde söylenmesi ile oluşan gizli bir koruma görevidir. Hem içsel nitelikleri (perde, tartım, tını oturtum vb.), hem de icra özellikleri (toplu söyleme, çalma, sahne vb.) bakımından bir anlamda modernize etmek. Niğde düğünleri ve müzisyenlerinin gizli bir kültürel aracılık görevi vardır. Kültürel toplulukların pek çoğunda görüldüğü gibi, Niğdeli müzisyenler ve dinler kitlenin müziğe ilişkin içselleştirdikeri sosyokültürel dizge ve değerlerin -birbirinden farkı olmayan dinamiklerdışlandığı, bunun yerine hem zamansal hem uzamsal olarak icraya dayalı sabitlenmiş varyasyonların gözardı edilmediği çok yönlü -özellikle ritmik yapıda- indirgenmiş bir halk müziğinin yeniden icadı gerçekleştirilmektedir. Niğde düğünlerinin özelliği gün içerisindeki süresinin uzunluğu, halen anonim Türk Halk müziği eserlerinin dügünlerde seslendiriliyor olması ve özellikle Ankara ve çevresine yakın olan bölgelerde yani Aksaray tarafındaki ilçe ve köylerde küyerelleşme etkisindeki Ankara müziklerinden etkilenerek türkülerdeki ritmik yapının giderek daha da hızlanmasıdır. Yörede dügün müzisyenliği yapanlar, Karanlıkdere köyü düğünlerine ünlü sanatçlların yüksek meblağlar ile çağırılmasının başlıca nedeninin, köylünün kendi reklamını yapmaya çalışması olarak değerlendirmektedirler. Bu nedenle köy özellikle Ortanadolu türkülerinin meşhur okuyucularının uğrak yeri olmuştur.

Niğde düğünlerini önemli kılan diğer bir faktör, "salon düğünü" kültürünün yeterince yaygınlaşmamış olmasıdır. Niğde çevresinde aynı kültürün görüldügü fakat büyük şehir konumundaki (Kayseri, Adana, Konya gibi) illerde salon kültürünün yaygınlaşmasından dolayı bağlama ve renk sazlar ile çalınıp söylenilen türküler yerini salondaki tek enstruman olan klavyeye bırakmaya başlamıştır.

Niğde düğünlerine katılan genç nesil, bu düğünlerde -belki de hafızasında hiç olmayan- büyük çoğunluğu TRT repertuvarında bulunan türküleri dinleme firsatı bulur. Dinler kitle dügünde duyduğu bu türküyü ya telefonuna kaydederek, yada internet aracılığı ile zamanla hafızasına kazır. Bu, Niğde dügünlerinin gelenek sürekliliği açısından önemini ortaya koymaktadır. Niğde yöresinin dügüüleri, yörenin tarihinin, yaşama biçiminin törenlerin gelenek ve göreneklerin bir sonraki kuşaklara aktarıldığı meclislerdir. Böylelikle türküler paylaşıldıkça ölümsüzleşir. Yörede görüştüğümüz 
müzisyenler, 'dü̈̆̈̈nler olmazsa gençler bu türküleri nereden duyup öğrenecekler, sayemizde türküleri dinliyorlar' diyerek şöyle devam etmişlerdir; 'biz müzisyenler olarak yeni çıkan eserlere yetişemiyoruz, geçler nasıl yetişsinler' diyerek aslında medyadaki yeni ya da yeniden okunan anonim eserlerin ne kadar hızlı bir değişim içerisinde olduğunu vurgulamaktadırlar. Bu bağlamda Niğde düğün çalgıcıları da kültürel aktarımcı rolünü üstlenmektedirler. Yöre düğünlerinde kültürel olgular zaman içerisinde içiçe geçmiş ve Türküler toplulukların siyasi tercihlerinin de bir yansıması şekline dönüşmüştür. Örneğin; Leylim ley türküsünü dinlerken yapılan zafer işaretinin karşısında aynı düğünde başka bir grup "Genç Osman" türküsünde kurt işareti yapmaktadır. Mahsuni Şerif'e ait 'Dilaver' türküsü sırf hareketli olduğu için siyasi yönü gözönünde bulundurulmaksızın hareketli türkü olarak çalınıp söylenebilmektedir.

Yukarıda bahsedilen büyük ya da küçük farklılıkların dışında Niğde dügünlerinin en önemli ortak noktası repertuvarını THM türkülerinin oluşturmasıdır. Bu bağlamda değerlendirildiğinde yöre düğünleri kültürün sürekliliğine büyük katkı sağlamaktadır. Uzun yıllar yörede söylenilen türkülerin dışında son yıllarda özellikle Ankara Türküleri adı altında küyerelleşmenin etkisi ile medya üzerinden topluma dinletilen türküler de yavaş yavaş dügüunlerde yerini almaya başlamıştır. Bu türkülerin yörede kabul görmesinin nedeni, bölgeye has olan ritmik yapı ve dizi (makam) özelliklerine çok yakın olmasıdır. Yöre dügünlerinde kırık hava türkülerin yınısıra, uzun hava formunda eserlerin bolca çalınıyor olması, gün içerisinde yaklaşık 14 ile 22 saat arasında devam eden uzun süreler düğünlerde farklı formların görülmesinde yan etkenlerdir. Yörede dügünler, dügünden ziyade Türk halk müziği konseri havasında geçmektedir. Yöre dügüülerini konserden ayıran özellikleri süre kısıtlaması olmaması ve türkülerin belirli bir sıralamaya göre çalınmaması yani her şeyin spontane gerçekleşiyor olmasıdır. 


\title{
EXTENDED ABSTRACT
}

\section{Sustainability of Tradition and Nigde Weddings and Musicians in Transfer of Cultural Heritage}

\author{
Resul Bağ1 \\ Niğde Ömer Halisdemir University
}

If culture is defined as practices in which members of a social group are influenced or learned by each other, act as a mediator in adaptation to the environment and are transferred from one generation to another through social learning, musical dynamics play an important role in the continuity of tradition. Increasingly encouraging a dynamic approach in this kind of work, weddings are the dominant task. The continuity of tradition is not to preserve a good heritage from the past, but to enrich it in accordance with the existing conditions and to pass it on to future generations. The authenticity of melodies is associated with a hereditary performance and tradition of creation. In this case, of course, it promotes the protection and promotion of musical works. The reorganization of the old songs in the wedding repertoires at certain times with some changes is as important as the practice of artistic production and participation. Wedding rituals are usually performed by professional musicians whose profession is musicianship. Ritualoriented musical events can be held occasionally later in the morning, starting at 08.00 in the morning, until 24.00 at night, the traces of the wedding motivate the audience to participate in the wedding. However, non-ritual-oriented musical activities are aimed at meeting the musical expectations of the participants who come to watch the wedding.

The wedding ceremony is one of the traditional transition rituals in our country and it lasts an average of two days in many regions today. The subject of the wedding ritual is in Niğde and its environs with different number of days and different practices. These rituals gain meaning with the contributions of professional musicians in Niğde. These 
musicians, especially in Niğde, are people from Nigde who live in the region. Generally, young people from Niğde, who started their profession in the master-apprentice relationship, continue to carry out this job professionally in their later years. Even musicianship is the only source of income for many. Musicians from Niğde offer music services in 3 different places:

The first is a 20-hour process that starts in the early hours of the morning in closed spaces, which can be defined as rooms or houses, and lasts until the morning of the call to prayer and even until sunrise. In such places and in the process, the ritual flow is coded at certain stages with specific weather and guided the passage. The second is a process that starts in the early morning hours and ends in the middle of the night in open-air venues in cities and villages, also called neighborhood weddings. The third is hall weddings, which last for 2 days and are designed to adapt to the technological life and current rituals.

We can basically divide Nigde and its surroundings into three parts. This distinction is mainly based on musical practices, and this distinction contains differences within itself. These groupings do not contain strict limits, but they exhibit exclusive features in musical activity. For example, in regions where there is a shoulder drum-shrill pipe (zurna) and wedding culture, there are also weddings with electro-long necked lute (bağlama) instrument and electro keyboard. All that is almost longer than the duration of a single common wedding other parts of Turkey. Throughout the day, Turkish Folk Music (THM) works songs with beaten (uzun hava) and beatless folk songs (kisa hava) - are performed and the folk songs of the religions are refreshed. Although the province of Niğde is unable to fit the wedding music culture into clear frames, we can list them in terms of application differences as follows.

The continuity of traditions is only possible if the societies adhere to their own culture, customs and traditions. Neighborhood weddings in Niğde province have an important place in the continuity of this continuity. It is of great importance for the continuity of folk music tradition that Turkish folk music melodies are mostly played and sung at 
the weddings. However, the continuation of culture adversely affects the performance of folk melodies as a product of popular culture in wedding halls which are becoming more and more widespread today. We can basically divide Nigde and its surroundings into three parts. This distinction is mainly based on musical practices and each section has its own differences. Although these sections do not contain certain limits, they may exhibit exclusive features in musical activity. For example, in regions where there is a wedding culture with shoulder drum-shrill pipe, it is also performed in weddings with electrolong necked lute and electro keyboard accompaniment. Almost all the wedding rituals in terms of a single public point of time is longer than the other regions of Turkey. During the day, Turkish Folk Music works - songs with beaten (uzun hava) and beatless folk songs (kısa hava) are performed and the folk memory of the listeners is refreshed. Although the wedding music culture in Niğde does not fit into clear frames, we can list it in terms of application differences as follows.

Çamardı, Ulukışla, Melendiz and Çiftlik; Weddings where drumzurna-oriented halay is common.

Bor and its surroundings; Weddings with electro binding and keyboard.

Fertek and Koyunlu; Wedding team consisting of Cümbüş, Violin, Clarinet and darbuka instruments called color saz.

Musicians from Niğde usually provide their jobs through their mobile phones because they serve their region. For the last 25 years, the musician profession in weddings as well as the master-apprentice relationship, as well as those who have studied or graduated in the department of music teaching at Niğde University have been continuing this profession professionally. Therefore, the positioning of wedding musicians from Niğde as a cultural tool is of particular importance. Although the conflict between culture and civilization is part of an ongoing conflict between tradition and modernity, another important aspect of examining musical practices by Niğde musicians is to determine the extent of cultural transformation by focusing on the change between past and present musical practices. 
These weddings, which have various predetermined stages within the traditional codes of conduct, can be divided into three as female centered, male centered and male centered. Because of these distinctions, two different groups of musicians are usually rented for weddings. In recent years, instead of hiring two different groups of musicians, a different application has started to be made by installing one of the sound systems in the place where women live with the help of technology. Wedding owners who are in good economic condition usually insist on hiring two separate groups and one of them is female musician. In and around Fertek, two different groups are preferred as classical reed group and anonymous reed group.

Depending on the changes in the process of industrialization and urbanization, the changes in our Turkish national culture are also reflected in our weddings. Due to all these factors, hall weddings enter our villages. In some regions that are sensitive about the continuity of the tradition and trying to maintain its cultural connection, great care is taken not to lose the essence of wedding traditions. Niğde is one of the cities where this care is taken. Niğde weddings are of great importance for the continuity of tradition and the transfer of cultural heritage. Although their limitations cannot be determined with clear lines, weddings in the Niğde region are divided into three according to the difference in theoretical practice. 1. Halay (Anatolian folk dance) oriented weddings with shoulder drum-shrill pipe instruments, 2 . Weddings focused on different timber instruments such as clarinet, çümbüş (mandolin with a metal body), fiddle, etc.) 3. Weddings focused on electro long necked lute-keyboard instrument.

The musicians working in the region are usually invited to the wedding by their own circle. However, due to the intense weddings in special times such as festive periods, it can also be invited to weddings in different regions in Niğde. Niğde weddings and musicians in weddings perform several functions of cultural mediation. The first of these is a secret protection task that is formed by singing local music at weddings. To modernize in terms of both internal qualities (pitch, rhythm, timbre, instrument-word harmony etc.) and performance 
characteristics (collective singing, performance, stage, etc.). Niğde weddings and musicians have a secret cultural mediation duty. The feature of Niğde weddings is the length of time during the day, the fact that anonymous Turkish Folk Music works are performed at weddings, and the rhythmic structure in the folk music is increasingly accelerated by being influenced by the globalization influences of Ankara, especially in the districts and villages close to Ankara and its surroundings. The main reason why famous musicians are invited to the weddings of Karanlıkdere village by the wedding musicians in the region is considered as the villagers trying to advertise themselves. For this reason, it is seen that this village is especially frequented by famous singers of Central Anatolian folk songs.

The young generation participating in Niğde weddings can find the opportunity to listen to folk songs, most of which are not in memory, in TRT repertoire. The audience either records this song on their phone or listens to it through the internet and receives it in memory. This situation reveals the importance of Nigde weddings in terms of continuity of tradition. The weddings of the Niğde region are the communities where the history, life style, ceremonies, traditions and customs of the region are transferred to the next generations. Thus, these songs become immortal as they are shared. The musicians interviewed in the region explained this situation as follows: if there are no weddings, these young people cannot hear and learn these songs, and thanks to us they listen to these songs. As musicians, we cannot keep up with the new songs, but how these young people will learn these new songs. In fact, they emphasize how rapidly the new or re-performed anonymous songs in the media are changing. In this context, Niğde wedding players play the role of cultural transmitters. Cultural phenomena intertwined in local weddings and folk songs became a reflection of the political preferences of the communities.

Apart from the big or small differences mentioned above, the most important common point of the Niğde weddings is the repertoire of Turkish Folk Music. In this context, local weddings contribute to the continuity of culture. Apart from folk songs sung in the region for many 
years, in recent years, especially with the influence of globalization under the name of Ankara folk songs played to the community through the media gradually began to take place in weddings. The reason that these folk songs are accepted in the region is that they show a very similarity to the rhythmic structure and maqam characteristics that are unique to the region. The fact that the songs are played a lot in the form of short and long weather at local weddings, and the long periods lasting between 14 and 22 hours during the day are the side factors in the appearance of different forms in weddings.

Weddings take place in the mood of Turkish Folk Music concert rather than wedding. What distinguishes local weddings from concerts is that there is no time limitation and that folk songs are not played in a certain order, that is, everything happens spontaneously.

\section{Kaynakça / References}

Altun, İ. (2004). Kandıra Türkmenlerinde doğum, evlenme ve ölüm. Kocaeli Yayınc Yayınları.

Arık, H. B. (2014, Mart 21). Kişisel görüşme. (R. Bağı, Röportaj Yapan)

Ataman, S. Y. (1992). Eski Türk dü̆̆̈̈nleri. Ankara: Kültür Bakanlığı.

Benedict, R. (2011). Kültür örüntüleri. İstanbul: İletişim Yayınları.

Berrakçay, O., ve Yükselsin, İ. Y. (2015). Deve güreşi ritüellerinde müzik ve müzisyenlik. Uluslararası Sosyal Araştırmalar Dergisi, 8(41), 1428-1443.

Bilen , E. (2015, Ocak 20). Kişisel görüşme. (R. Bağı, Röportaj Yapan)

Coşkun, İ. (2018, Aralık 18). Kişisel görüşme. (R. Bağı, Röportaj Yapan)

Dağlı , M. (2015, Nisan 07). Kişisel görüşme. (R. Bağı, Röportaj Yapan)

Eagleton, T. (2005). Kültür yorumları. İstanbul: Sena Ofset.

Erol, A. (2009). Müzik üzerine düşünmek. İstanbul: Bağlam Yayınc1lı. Güngör, N. (2017, Mart 25). Kişisel görüşme. (R. Bağı, Röportaj Yapan)

Kaplan, A. (2008). Kültürel müzikoloji. İstanbul: Bağlam Yayınları.

Lavenda, R. H., ve Schultz, E. A. (2017). Kültürel antropoloji. Ankara: Doğu Batı Yayınları 205.

Nettl, B. (1983). The study of ethnomusicology. Illinois: University Of Illinois Press.

Orhan, E. (2016, Kasım 11). Kişisel görüşme. (R. Bağı, Röportaj Yapan)

Özdamar, K. (2017, Ocak 21). Kişisel görüşme. (R. Bağı, Röportaj Yapan) 
Sancaktaroğlu, İ. (2016, Ekim 25). Kişisel görüşme. (R. Bağı, Röportaj Yapan) Sarıteke, S. O. (2016, Haziran 17). Kişisel görüşme. (R. Bağı, Röportaj Yapan) Sevinç, S. Ş. (2016, Mart 21). kişisel görüşme. (R. Bağı, Röportaj Yapan)

Turner, B. S. (2006). The cambridge dictionary of sociology. Cambridge: Cambridge University Press.

Yaltırık, B., ve Kumpasoğlu, B. (2015). Kültürel kimliğin inşası ve kültürel aracılık özelinde Hasan Ropodlu örnek olayı. UHMAD Uluslararası Hakemli Müzik Araştırmaları Dergisi, 2(3), 36-45.

Yaşar, N. (2018, Aralık 2). Kişisel görüşme. (R. Bağı, Röportaj Yapan)

Yükselsin, İ. Y. (2014). Kültürel aracılık, Romanlar (Çingeneler) ve müzik: Bir Rumeli halk ezgisinin kırkpınar güreş havasına dönüştürülmesi örnek olayı. Uluslararası Sosyal Araştırmalar Dergisi, 7(34), 713-730.

\section{Kaynakça Bilgisi / Citation Information}

Bağı, R. (2019). Geleneğin sürekliliği ve kültürel mirasın aktarımında Niğde dügünleri ve müzisyenler. OPUS-Uluslararası Toplum Araştırmaları Dergisi, 13(19), 1225-1254. DOI: 10.26466/opus.593570. 